\title{
Scheme of soil stability losses in the laboratory tray
}

\author{
Alexander Kremnev ${ }^{1}$, Nikolay Vishnyakov ${ }^{1, *}$ and Victoria Ermachenko ${ }^{1}$ \\ ${ }^{1}$ Polotsk State University, 211440, Blokhina 29, Novopolotsk, Belarus
}

\begin{abstract}
The object of the research is the diagram of the stability loss of the soil foundation. Currently, there are still discussions about how the stability of the subgrade undergoes the combined action of vertical and horizontal loads. Most often, in the calculation, the sliding surface is taken to be circular. Whether this is true, especially for a heterogeneous or anisotropic base, is an important question today. In the work, chute tests were carried out, with modeling of the scheme of loss of stability of anisotropic and isotropic bases and results were obtained that confirm the formation of a circular cylindrical sliding surface.
\end{abstract}

Key words: anisotropy, soil bases, circular sliding surface, soil stability losses, laboratory tray.

\section{Introduction}

It should be noted that most of the theories currently used for calculating subgrade bases assume that the foundations are homogeneous and isotropic. To analyze the stress-strain state of such bases, the well-known solutions of the linear theory of elasticity, the theory of limiting equilibrium are used. However, it is reliably known that most soils are heterogeneous in nature.

The relevance of the issue of taking into account anisotropic base is due to the fact that at any time due to the action of natural factors (freezing, flooding, flooding, etc.) any homogeneous base can turn, at least, into anisotropic, which, in turn, can cause the need for reinforcement. This procedure is quite lengthy, associated with the cost of a large amount of material and labor resources and the disruption of the normal operation of existing buildings, thus a method that takes into account the factor of anisotropy allows to reduce material and technical resources.

\section{Methods}

The tests were carried out in a tray with dimensions of $1.5 \times 1.0 \times 0.35 \mathrm{~m}$, welded from metal corners and pipes, the front side of which is equipped with plexiglass $12 \mathrm{~mm}$ thick, which makes it possible to observe the nature of deformation and the formation of a sliding surface in the simulated soil base.

\footnotetext{
*Corresponding author: vnnpsu@mail.ru
} 
A $30 \times 30 \mathrm{~cm}$ metal plate was taken as a foundation model. A triangular wedge was used to apply a load at an angle of $20^{\circ}$. A hydraulic jack, complete with an oil station, was installed on the wedge. The oil station is equipped with a pressure gauge to measure pressure. The fixation of the magnitude of horizontal and vertical displacements was carried out using 6PAO deflection meters. The test setup is shown in Figure 1.

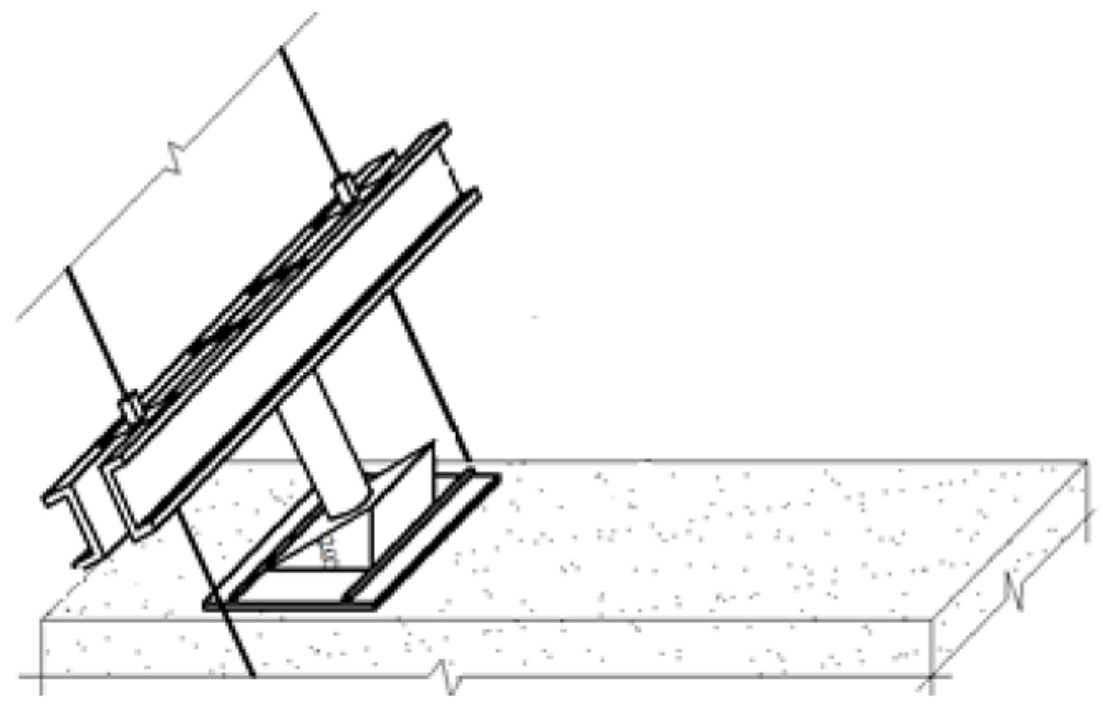

Fig.1.Test setup diagram.

The load on the punch was applied as a resultant from vertical and horizontal forces. At the first stage, tests were carried out for loads applied at the following angles: $30^{\circ}, 25^{\circ}$, $20^{\circ}, 15^{\circ}$. In this case, only the volume of soil involved in the formation of the vortex prism was recorded. It was found that the most optimal loading angle is $20^{\circ}$. With the accepted dimensions of the tray and the size of the stamp, this angle allows one to observe the most complete picture of the stability loss of the base. In the second stage, at a fixed angle of application of the load of $20^{\circ}$, tests were carried out for homogeneous and anisotropic subsoils.

The die load was transferred in steps with a step of $2.5 \mathrm{kN}$. Each loading step was maintained until the onset of conditional stabilization. In this case, the vertical and horizontal movements of the stamp were recorded.

The test continued until the complete loss of stability of the foundation model with the formation of a soil shear surface and a surface uplift.

\section{Tests with a homogeneous sand base}

The filling of a homogeneous sandy base was carried out with medium sand. To visualize the process of deformation of the subgrade, test strips were made using dolomite flour. The stripes were created only near the plexiglass, the thickness of the filling was $0.5 \mathrm{~cm}$, with a step of $3 \mathrm{~cm}$ vertically. A homogeneous sandy base with strips of dolomite flour before testing is shown in Figure 2.

To ensure the uniformity of the base, the soil was compacted manually, using a rammer in layers. 


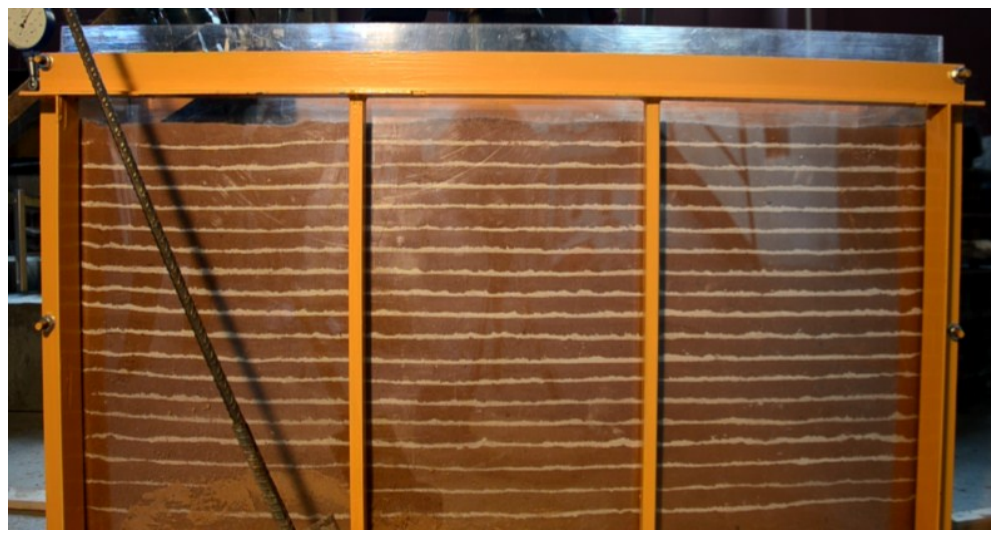

Fig.2. Uniform sandy base before testing.

In the course of the experiment, at 5 and $7.5 \mathrm{kN}$, a pronounced wedge-shaped figure was observed under the punch bottom, after which significant horizontal displacements were visible and at $12.5 \mathrm{kN}$ the foundation lost its stability (Fig. 3).

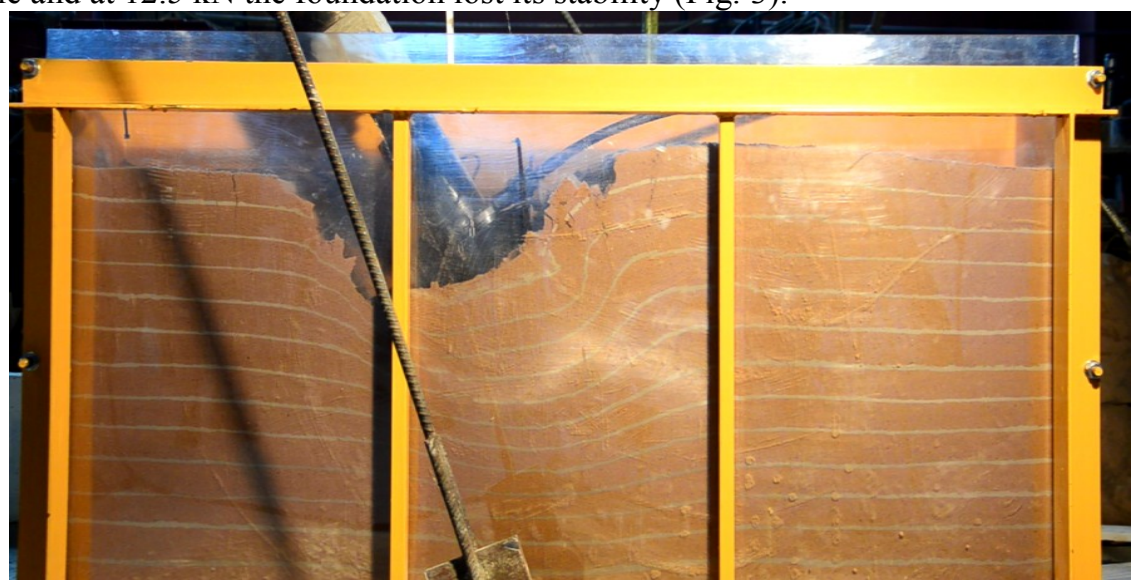

Fig.3. Loss of stability of a homogeneous sandy base.

Generalized test results are shown in table 1:

Table 1. Results of tests of the sand base.

\begin{tabular}{|c|c|c|c|}
\hline $\begin{array}{c}\text { Die load, } \\
\mathrm{kN}\end{array}$ & $\begin{array}{c}\text { Horizontal } \\
\text { movement of the } \\
\text { stamp, } \mathrm{mm}\end{array}$ & $\begin{array}{c}\text { Vertical } \\
\text { movement of the } \\
\text { stamp, } \mathrm{mm}\end{array}$ & Notes \\
\hline 2,5 & 6,58 & 12,30 & Compaction of soil under the stamp sole \\
\hline 5,0 & 21,55 & 30,92 & Formation of a wedge by compacted soil \\
\hline 7,5 & 33,18 & 46,31 & $\begin{array}{c}\text { Distinct wedge-shaped figure under the stamp } \\
\text { sole }\end{array}$ \\
\hline 10,0 & 52,72 & 67,49 & Significant die movements \\
\hline 12,5 & 108,16 & 141,43 & Loss of foundation stability \\
\hline
\end{tabular}

After the test, graphs of the dependence of horizontal and vertical deformations on the load were plotted (Figure 4.5) 


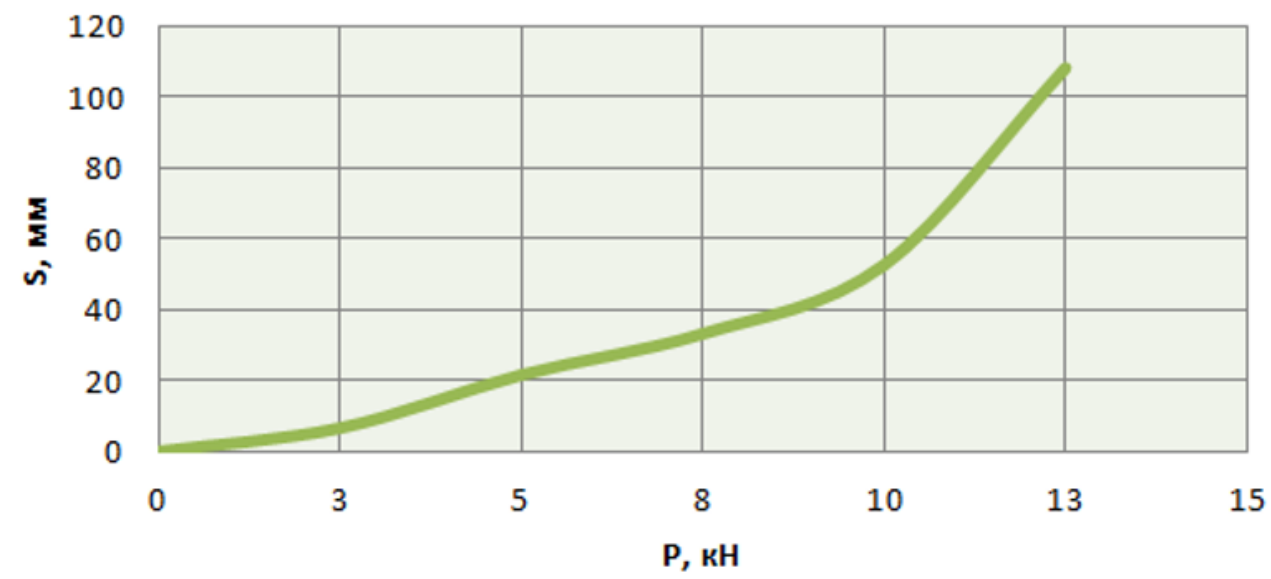

Fig.4. Graph of the deformation of the sand base in the horizontal direction.

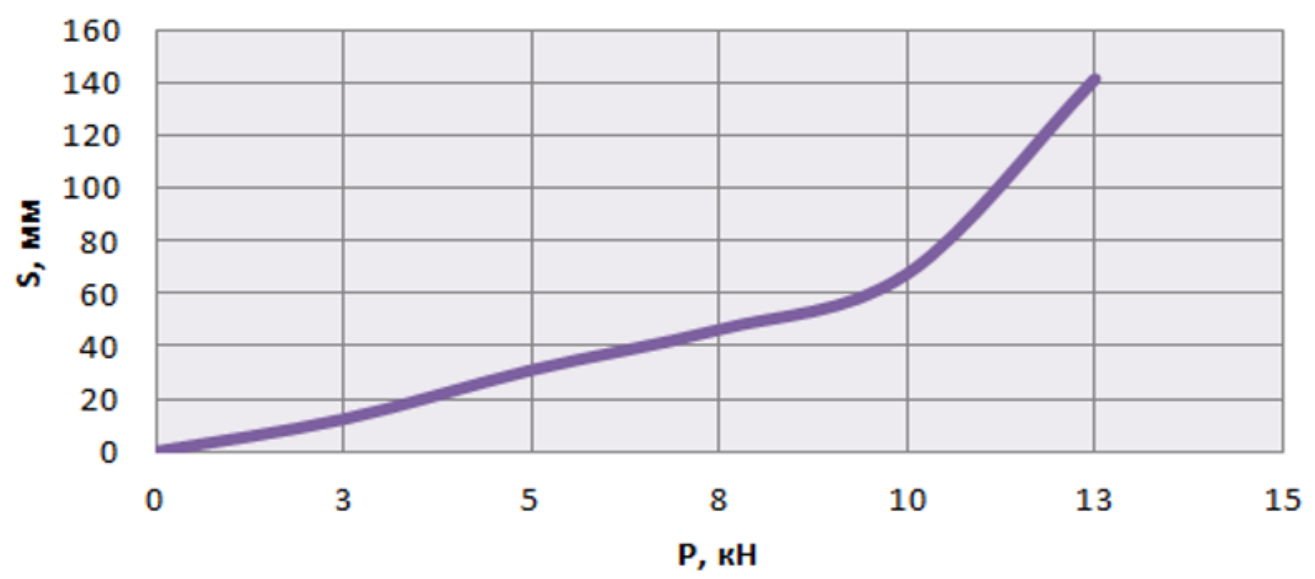

Fig.5. Graph of the deformation of the sand base in the vertical direction.

As a result of tests carried out with a sand base, loss of stability occurred at a load on the punch of $12.5 \mathrm{kN}$ and the failure showed a sliding surface close to circular cylindrical.

\section{Tests with anisotropic sandy-shale base}

The anisotropic subgrade model was created from two materials: medium sand and interlayers of bentonite clay.

2 variants of modeling an anisotropic base were carried out:

- In the first case, thick layers of bentonite clay, $2.5 \mathrm{~cm}$ thick, settled every $8 \mathrm{~cm}$ of sand.

- In the second case, $0.5 \mathrm{~cm}$ of clay through $4 \mathrm{~cm}$ of sand.

The first variant of modeling an anisotropic sandy-argillaceous base with interlayers of bentonite clay $2.5 \mathrm{~cm}$ thick before deformation is shown in Figure 6 . The soil, as in the case of a homogeneous base, was compacted manually using a rammer. 


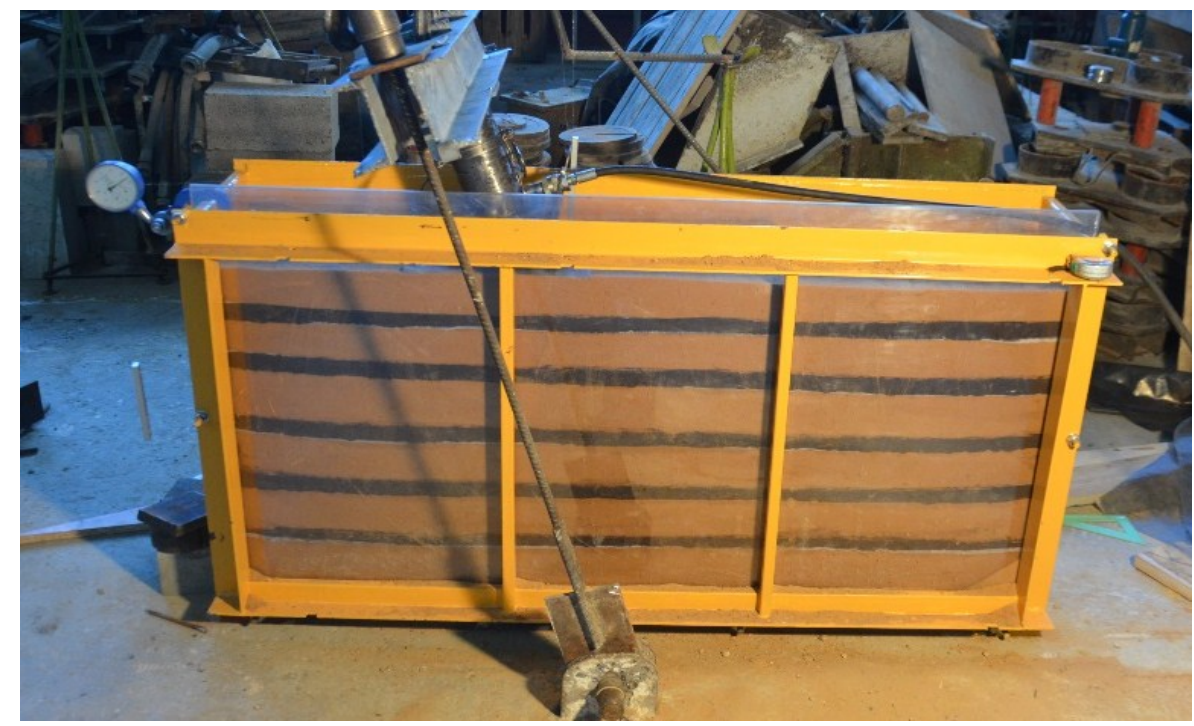

Fig.6. Anisotropic sandy-argillaceous base before testing.

The nature of the deformation of the anisotropic base was different from the isotropic one. The loss of stability of the foundation occurred at a significantly lower load on the stamp - only $2.5 \mathrm{kN}$, and was accompanied by a shift of the compacted soil core under the stamp along a clearly visible sliding surface close to a circular cylindrical and surface upwelling of the soil. In this case, a shift occurred along the interlayer of bentonite clay, as soon as the lower boundary of the compacted core reached the interlayer (Fig. 7).

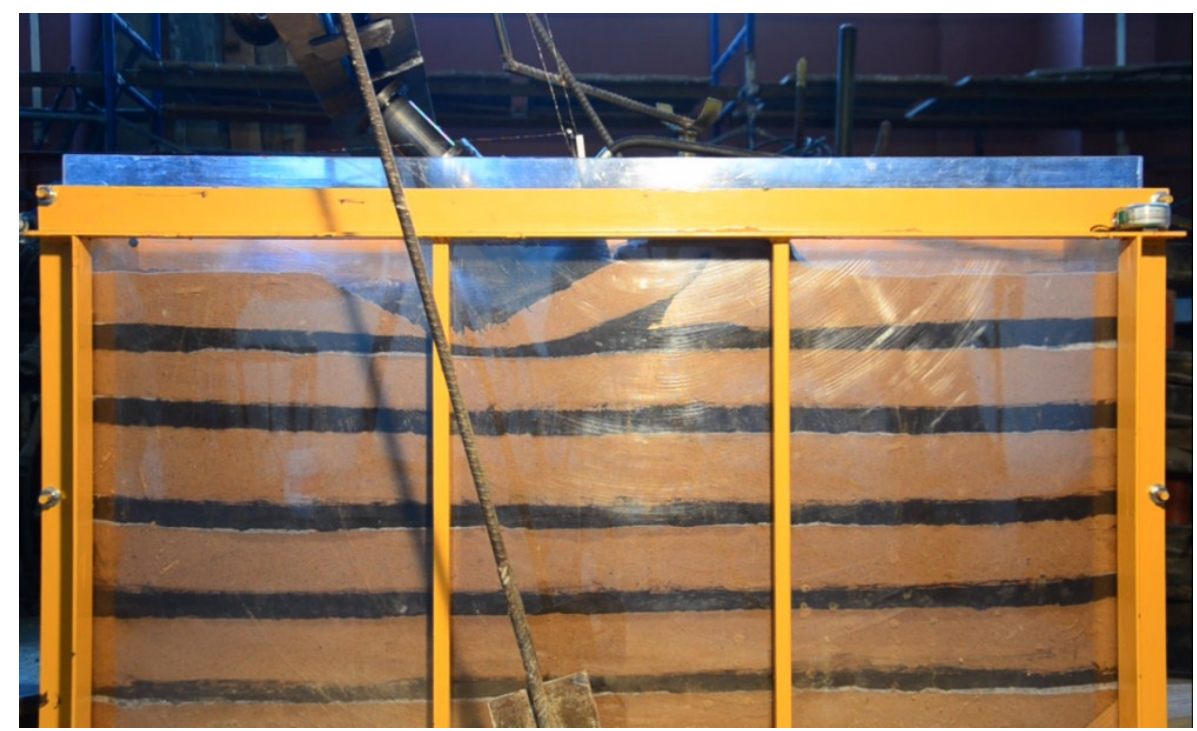

Fig.7. Loss of stability of anisotropic sandy-argillaceous base with layers of $2.5 \mathrm{~cm}$.

Repeating the experiment with thinner clay interlayers, $0.5 \mathrm{~cm}$ thick, it is clearly seen that the nature of the loss of stability of the base is similar to the shear with thicker interlayers, but the shift occurred, but at a greater depth (Fig. 8). The results of the experiment are presented in table 2 . 


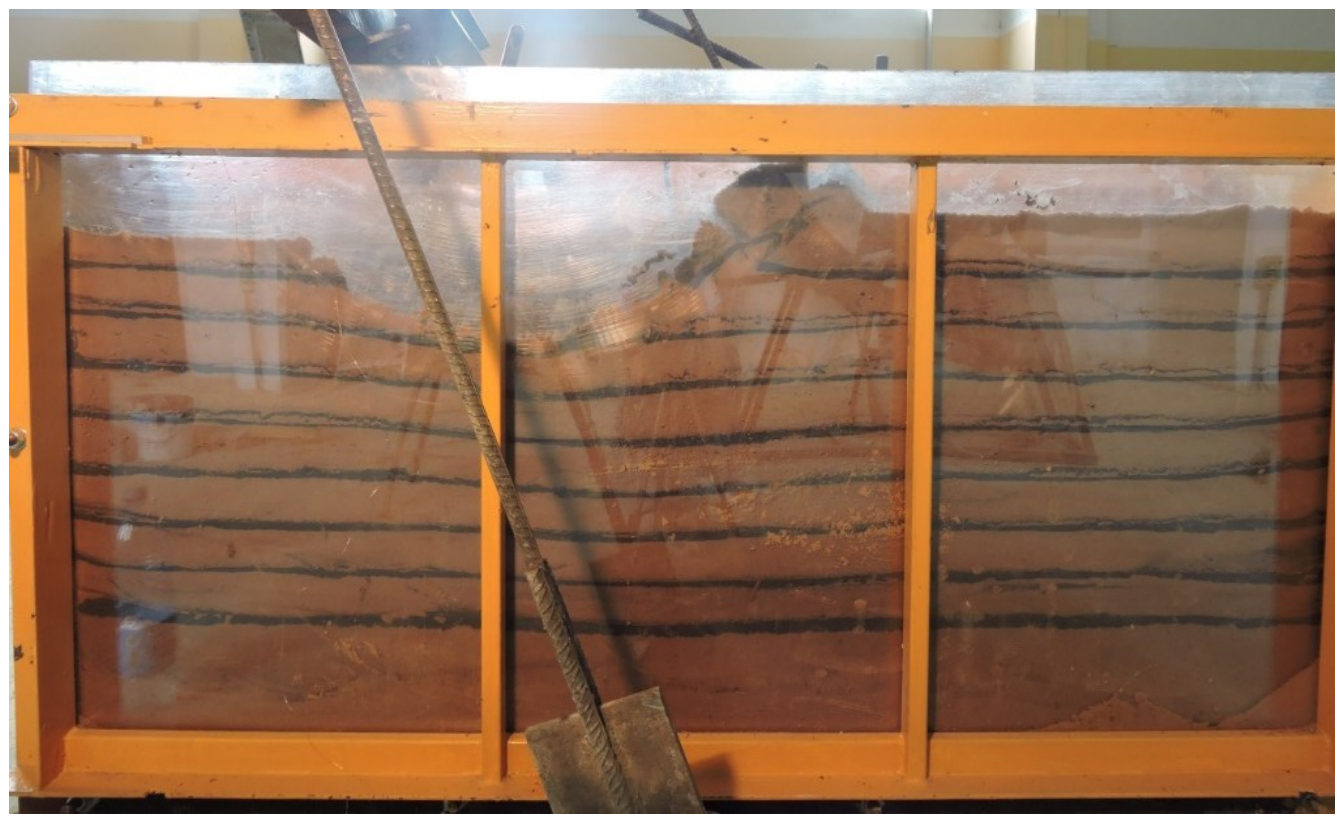

Fig.8. Loss of stability of a sandy-clay base with $0.5 \mathrm{~cm}$ interlayers.

Table 2. Test results of sandy-clay base.

\begin{tabular}{|c|c|c|c|}
\hline Die load, $\mathrm{kN}$ & $\begin{array}{c}\text { Horizontal } \\
\text { movement, } \mathrm{mm}\end{array}$ & $\begin{array}{c}\text { Vertical } \\
\text { movement, } \mathrm{mm}\end{array}$ & Notes \\
\hline 2,5 & 4,68 & 0,54 & Compaction of soil under the stamp sole \\
\hline 3,0 & 54,47 & 0,92 & $\begin{array}{c}\text { Significant horizontal movement of the } \\
\text { stamp }\end{array}$ \\
\hline 3,5 & 79,85 & 3,58 & Loss of stability of the subgrade \\
\hline
\end{tabular}

Based on the data obtained, graphs of the dependence of horizontal and vertical deformations on the load were constructed (Fig. 9, 10).

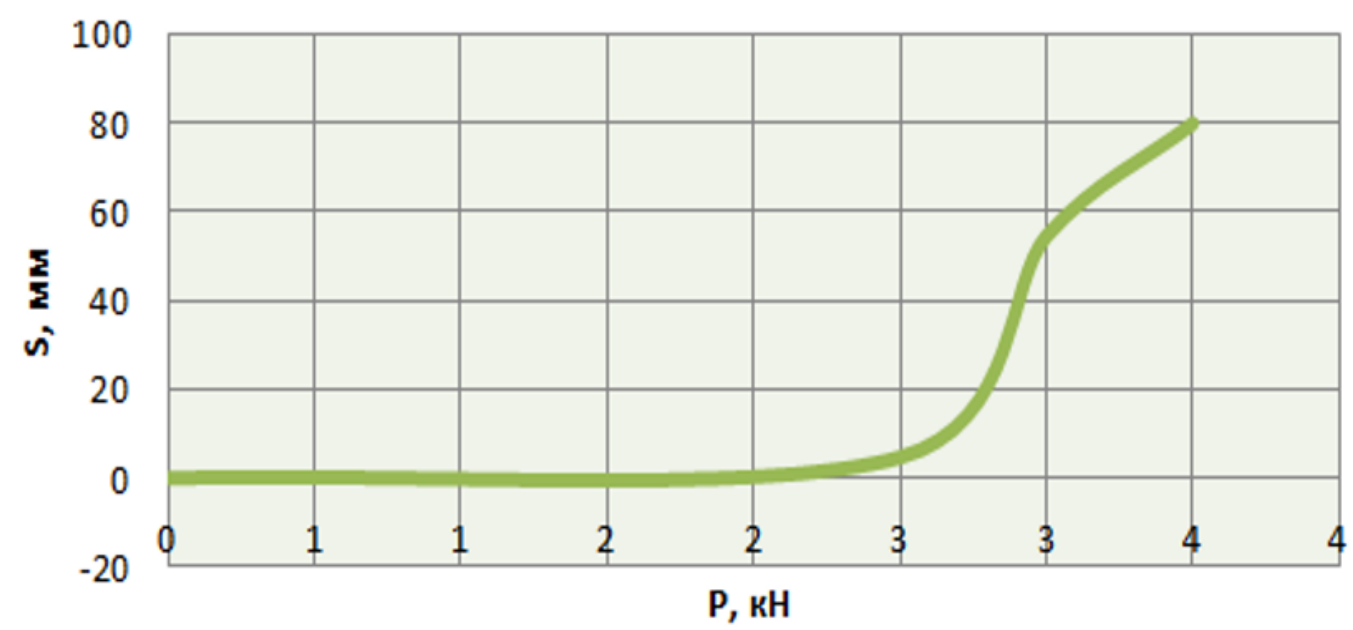

Fig.9. Graph of deformation of anisotropic sandy-argillaceous base in the horizontal direction. 


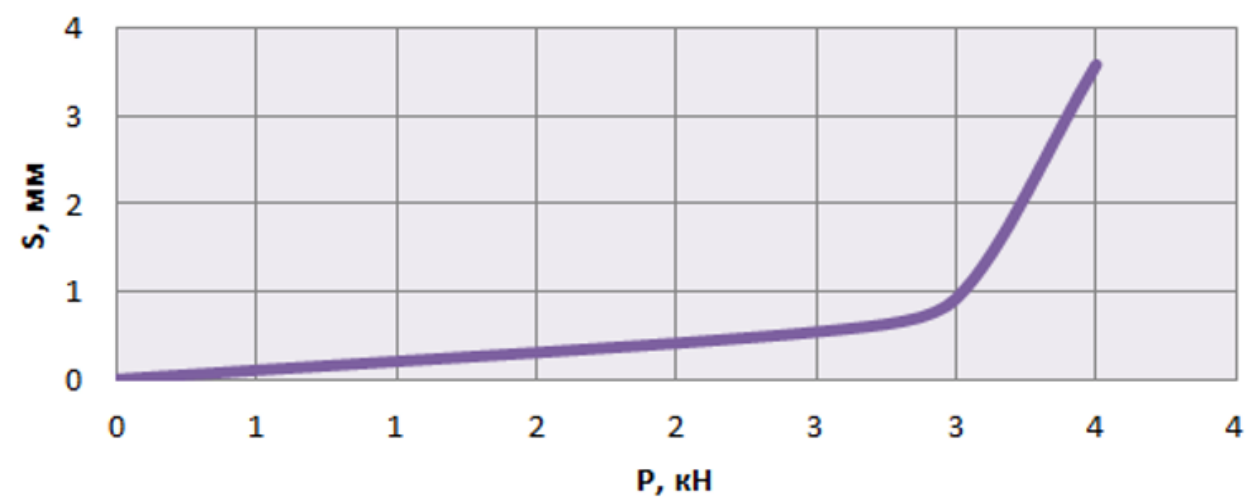

Fig.10. Graph of deformation of anisotropic sandy-argillaceous base in the vertical direction.

During the analysis of the outlines of sliding surfaces, it was found that, in general, the shift of one part of the soil relative to another occurred along a surface close to a circular cylindrical one (Fig. 11).

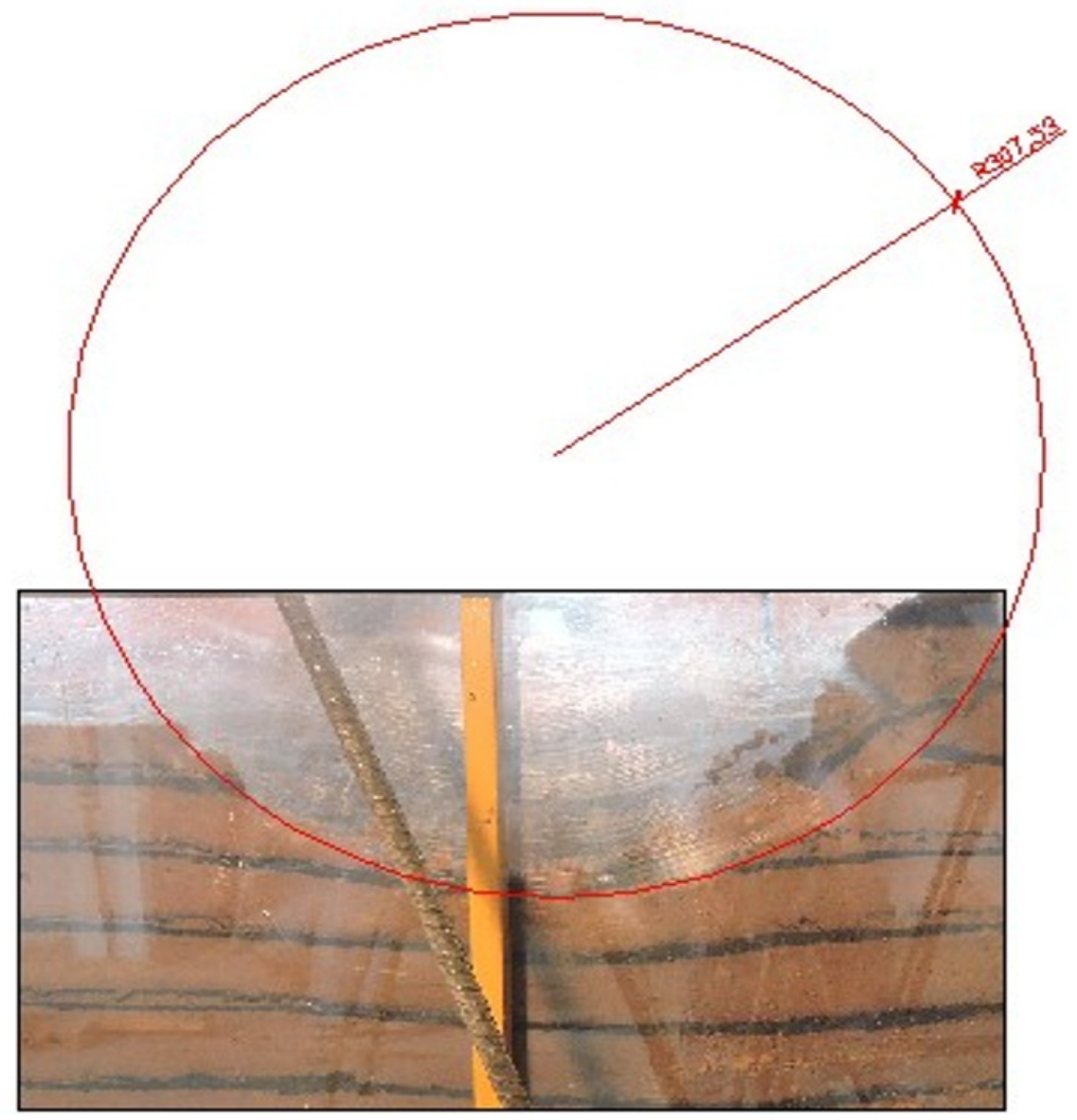

Fig.11. Approximation of the sliding surface by a circular cylindrical surface. 


\section{Conclusion}

Thus, laboratory studies of soil foundation models in trough conditions have shown that the loss of stability of a soil mass with pronounced horizontal anisotropy under the action of vertical and horizontal loads also occurs on a surface close to a circular cylindrical one. It should be noted that the sliding surface at the base with pronounced anisotropy is initially formed along a weak interlayer. In the first case, the sliding surface was formed in the upper weak layer, in the second case in the second. With respect to weak interlayers, the circular-cylindrical sliding surface in the first and in the second case passed along a tangent.

\section{Reference}

1. A. Gadre, R. Dobry, Lateral cyclic loading centrifuge tests on square embedded footing. Journal Geotechnical and Geoenvironmental Engineering. 124. pp. 1128-1138 (1998)

2. J. D. Murff, T. W. Miller, Stability of offshore gravity structure foundations by the upper-bound method, Proceedings of the Offshore Technology Conference, 3, pp. 147$154(1977 b)$

3. Y. Maeda, Study on application of velocity field method in evaluation of bearing capacity of foundation, Kyushu University doctoral thesis, 2003

4. T. Schanz, Zur Modellierung des mechanischen Verhaltens von Rei bungsmaterialien // Mitt. Inst. fur Geotechnik 45. Universita..t Stutt gart. - Stuttgart. - 152 S. (1998)

5. N.N. Vishnyakov, A.P. Kremnev Bearing capacity of the foundations of spacer structures, taking into account the anisotropy of the strength properties of soils Materials of the International Conference, Minsk, (2018)

6. A. Kremniou, N. Vishniakov, Anisotropy of the Strength Properties of Clays of the Clays of the North of Belarus//Historical experience and challenges of geotechnical problems in Baltic Sea region $/ / 13^{\text {th }}$ Baltic Sea Region Geotechnical Conference, Vilnius, Lithuania, (2016)

7. O.A. Korobova, Analysis of the results of theoretical and experimental studies of the stress-strain state of anisotropic soils and subsoil foundations. - Polzunovsky Almanac, (2001). - [electronic resource]. - access mode: www.vc.secna.ru: 8080/Books/Files/ 2001-02/10/pap_10.html

8. T. Schanz, P.A. Vermeer, P.G. Bonnier, The HardeningSoil Model: Formulation and verification // Beyond 2000 in Computational Ge otechnics. - Balkema, Rotterdam, (1999). - P. 281-290. http://www.unistuttgart.de/igs/content/publications/40.pdf

9. A.P. Kremniov, D.U. Sobolevski, D.V. Skoryk, THE DEFINITION OF FRICTION AND COHESION PARAMETERS OF REINFORCED SOILS. - Доклад на Международной научно-практической конференции, Астана, (2002)

10. I.E. Pavlovskaya, Polotsk glacial-lake basin: structure, relief, history of development / I.E. Pavlovskaya. - Minsk: Navuka i tekhnika. - 128 p., (1994)

11. A.P. Kremnev, Determination of the most dangerous sliding surface when calculating the stability of slopes by the method of circular cylindrical sliding surfaces / A.P. Kremnev, D.O. Glukhov, N.N. Vishnyakov // Bulletin of the Polotsk State University PolotskSU theta. Series F, Applied Sciences. Building. - pp. 37-41 (2011)

12. A.A. Kalyaev, To the calculation of the stability of the foundations of massive structures on sandy soils / A.A. Kalayev // Foundations, foundations and soil mechanics. - No. 5. - pp. 3-6 (1962)

13. G Meyerhof, The bearing capacity of foundation under eccentric and inclined loads, Proc.3rd Int. Conf. Soil Mech. and Found. Eng.: pp. 4-24 (1953)

14. R. Bellotti, M. Jamiolkowski, D.F. Lo Presti, D.A. O’Neill, Anisotropy of small strain stiffness in Ticino sand, Géotechnique, 46(1), pp. 115-131 (1996) 
15. A. Casagrande, N. Carillo, Shear failure of anisotropic materials, Journal of Boston Society of Civil Engineering, 31(4), pp. 74-87 (1944)

16. C. Cherubini, Reliability evaluation of shallow foundation bearing capacity on $c^{\prime}, \varphi^{\prime}$ soils, Canadian Geotechnical Journal, 37(1), pp. 264-269 (2000)

17. J.M. Duncan, H.B. Seed, Anisotropy and stress reorientation in clay, Journal of the Soil Mechanics and Foundations Division, ASCE, 92(SM5), pp. 21-50 (1966)

18. R.E. Gibson, The analytical method in soil mechanics, Géotechnique, 24(2), pp. 115140 (1974)

19. M. Jamiolkowski, R. Lancellotta, D.C.F. Lo Presti, Remarks on the stiffness at small strains of six Italian clays, Proceedings of the International Symposium on the Prefailure Deformation Characteristics of Geomaterials, Hokkaido, Japan, Vol. 2, pp. 817836 (1995)

20. V. Jovicic, M.R. Coop, The measurement of stiffness anisotropy in clays with bender element tests in the triaxial apparatus, Geotechnical Testing Journal (GTJODJ), 21(1), pp. 3-10 (1998) 